\title{
OUTRIGGER TOPOLOGY AND BEHAVIOUR
}

\author{
Goman W.M. Ho \\ Arup, Level 5, 80 Tat Chee Avenue, Kowloon Tong, Hong Kong \\ (E-mail: goman.ho@arup.com)
}

Received: 23 February 2012; Revised: 10 September 2015; Accepted: 30 September 2015

\begin{abstract}
The structural efficiency of tall buildings heavily depends on their stiffness and lateral resistance capacity. Among those structural systems for tall buildings, outriggers system is the most common one for buildings with a relatively regular floor plan. Research in outriggers system is relatively limited and usually focuses on the optimal locations/levels of outrigger only. However, the locations of the outriggers are usually dictated by the functional use of the tall buildings and outriggers are usually located in the less commercial valuable floors such as mechanical or refuge floors. Because of this limitation, the topology of outriggers becomes an important element in providing an optimum design. Furthermore, most engineers considered that the performance of buildings is a linear relationship with the stiffness and the critical load of the outriggers. Nevertheless, this is not always true if the ultimate design load condition is being considered. This paper starts with various topologies of outrigger which are commonly used in practice; studies their stability behaviour, compares their stiffness and finally their ultimate load capacity. Examples demonstrate that for some outriggers geometry arrangement or topologies which delivered maximum stiffness and critical loads do not always yield the highest ultimate load capacity even for same outrigger member sizes.
\end{abstract}

DOI: 10.18057/IJASC.2016.12.2.1

Keywords : Tall buildings, outrigger systems

\section{INTRODUCTION}

The race to the sky started from the time of Tower of Babel following the invention of bricks. Nowadays, engineers use reinforced concrete, steel or composite material of steel and concrete to build high-rise buildings. Furthermore, various lateral structural systems such as shear walls, core-perimeter frame, tube-in-tube, core-outriggers with or without belt truss and mega frame etc. were developed. Ali and Moon [1] had a comprehensive review on the development of structural systems for tall buildings. Among the Interior Structures, "outrigger structures" is the category with efficient height limit up to 150 storeys. Hong Kong Cheung Kong Center (290m), Hong Kong IFC2 $(380 \mathrm{~m})$, Hong Kong ICC (450m), Taipei $101(509 \mathrm{~m})$ are typical well known tall building examples with outrigger systems.

The first building with elevators was the Equitable Life Assurance Building in New York completed in 1870 . This $40 \mathrm{~m}$ tall building was named as the world first tall building. The structural system is just simply framed building. With the height of buildings increasing, stiffness becomes an important issue. By simple engineering principle, the lateral resistance increases if the moment arm of building can be stretch out from the core to the extreme perimeter. Therefore, engineers started considering using stiff beams to connect both the core and the perimeter tube. It is obvious that the stiffer the beam, the further increase in lateral stiffness. Once buildings became taller, it was very difficult to adopt the "stiff" beam concept as the depth of the "stiff" beam would be as deep as a wall. Concrete outrigger systems were therefore developed. Shankar Nair [2] proposed the concept of "Virtual Outrigger" but engineers must make sure that the stiffened coupled floors and the vertical perimeter structures can provide sufficient stiffness to behave as outriggers. 
After World War II, the use of steel in tall buildings became popular because of the speed of construction and reduction in labour cost etc. With buildings with typical slenderness ratio and taller than 40 storeys, the previous "stiff" beam method is replaced by single or double story high steel truss. Although the use of outriggers is getting more widespread, research in outrigger systems is still very limited. Taranath [3], Stafford Smith [4], Gerasimidis et al [5] and Fawiza et al [6] studies focus on the overall efficiency of outriggers in tall buildings in controlling drifts and optimum locations of outriggers. Nevertheless, the possible locations for which can allow the designers to install the outriggers system are limited by the function of the buildings. In practice, outriggers are limited to be installed in mechanical or refugee floors instead of "optimum" locations. Ideally outriggers should be as deep as possible and therefore engineers often request double story height space for outriggers. In China, refuge floors are required for every 15 floors. Hence, in some buildings, the floor spaces which can allow for outriggers to be installed are limited to be single story height. Therefore, study on optimum topology of outrigger layout rather than the optimum locations of outriggers is needed. To the knowledge of the author, there is no literature on the topology of outriggers and its effect to stiffness and strength which is publicly available.

Also, the belief that the performance of tall buildings against drift is a linear function of outrigger stiffness leads to a tendency of providing oversize and overstiff outriggers in tall buildings. However, wind loading is not the only lateral load for tall buildings; seismic resistance is also an important factor for considerations in some area. Therefore, a balance for the stiffness, strength and ductility of the outriggers should be an area which engineers should pay special attention.

Outriggers increase the stiffness of buildings by means of converting the lateral forces into push (compression) and pull (tension) forces in the perimeter structures. Hence, outriggers are required to resist reverse and cyclic loading. From engineering principle, the topology for outrigger system should be symmetric to both upward and downward load such that it provides similar performance in all load cases. If symmetric topology cannot be used, the designer must be aware of the behaviour of outriggers under cyclic load.

\section{TOPOLOGY OF OUTRIGGERS}

With reference to most of the aforementioned text books, the typical diagrams for outriggers are as Figure 1. However, from a practical engineering point of view, these layout are neither possible nor efficient. Figure 1a shows an ideal situation for concrete outriggers. In practice, it is not possible to have a complete solid concrete wall between core and perimeter frame as doorways must be required. With a door access, the stiffness of concrete outriggers will greatly be reduced. Figure $1 \mathrm{~b}$ shows a braced steel core and steel truss as outrigger while 1c shows a concrete core with simple cross braces as outriggers. For presentation purposes, these diagrams are clean and clear. However, in reality, the topologies for outriggers are very different and subject to a lot of co-ordination between architects, structural and building service engineers. 


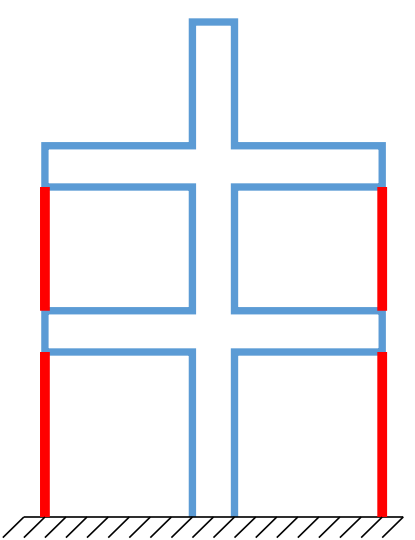

1a

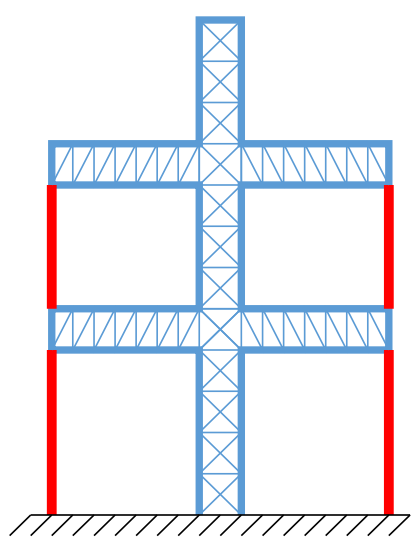

$1 \mathrm{~b}$

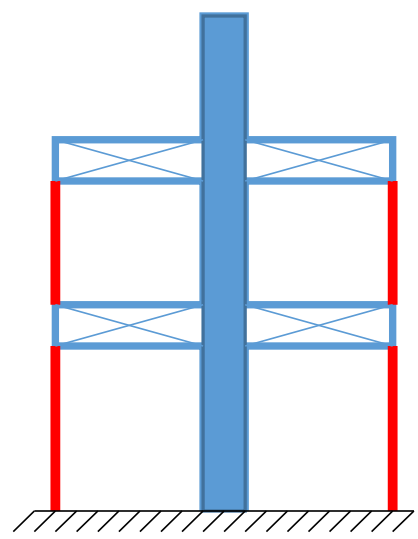

$1 \mathrm{c}$

Figure 1. Typical Diagrammatic Drawings for Outrigger Systems

It is not possible to study all the topological options for outriggers. Therefore, the most practical and common samples are selected in this studies. Figure 2 indicates a typical example with design constraints- Double story space $(2 \times 4.2 \mathrm{~m})$ between core and perimeter frame (13m span).

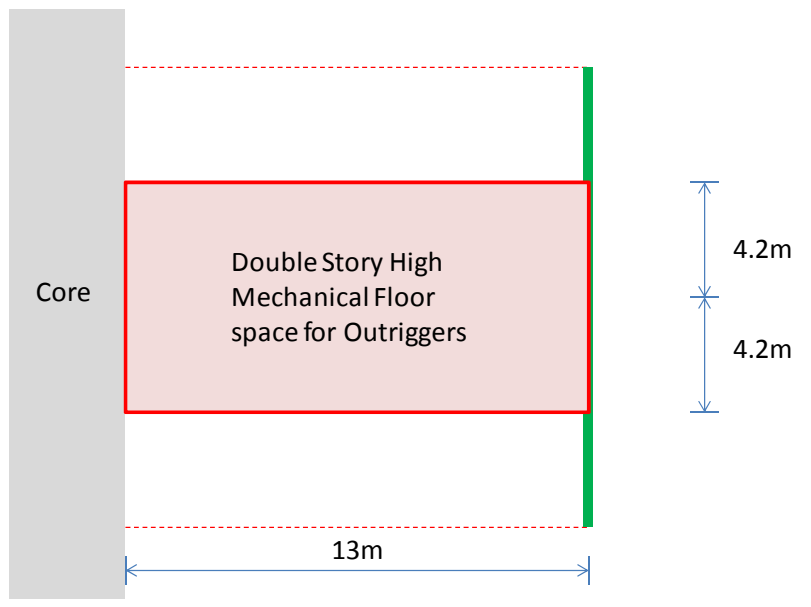

Figure 2. Design Constraints for Outriggers

Based on same space constraints, four practical topologies of outriggers are presented in Figures 3, 4 and 5. Figure 3 is a " $>$ " shaped outriggers as topology A. Figure 4 shows options B which is also as simple as topology A with bottom chord to be in the same level of floor. Figure $5 \mathrm{a}$ and $\mathrm{b}$ show topology $\mathrm{C}$ and $\mathrm{D}$ respectively. Both topology $\mathrm{C}$ and $\mathrm{D}$ are basically identical except there is no vertical member in topology $\mathrm{D}$ in comparsion with $\mathrm{C}$. To demonstrate the effect of stiffness, two kinds of member sizes are used. They are either fabricated square hollow section (SHS) of $1000 \mathrm{~mm} \times 1000 \mathrm{~mm} \times 50 \mathrm{~mm} \times 50 \mathrm{~mm}$ or Universal Beam (UB)UB304x127x42. The latter (UB) example is for reference and comparison purpose only as such member sizes are generally too small in practice. However, it provides the idea that the behaviour of outriggers varies with its member stiffness even with no topology change. All connections are assumed to be fully rigid except the vertical load applied to the tips of outriggers are pure vertical and conservative. All connections are assumed to be rigid because in most practical cases, outrigger members are heavy so designing a pinned connection would not be justifiable. 


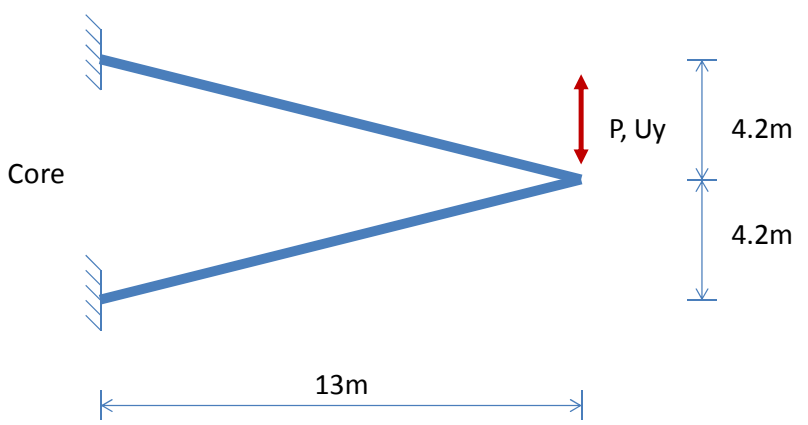

Figure 3. Topology A

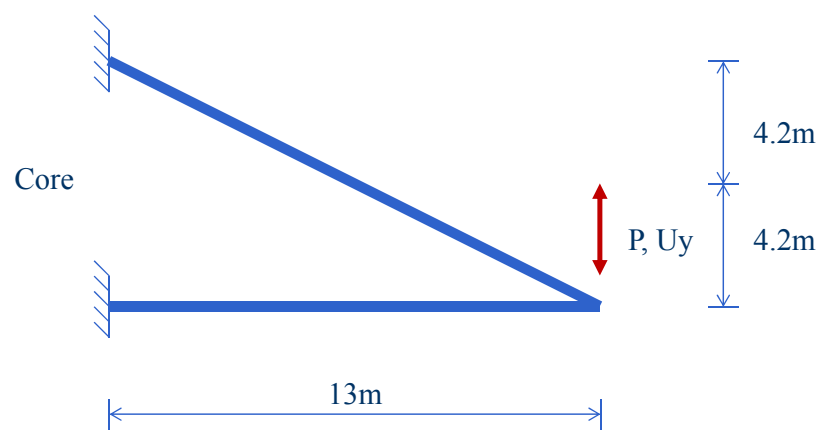

Figure 4. Topology B

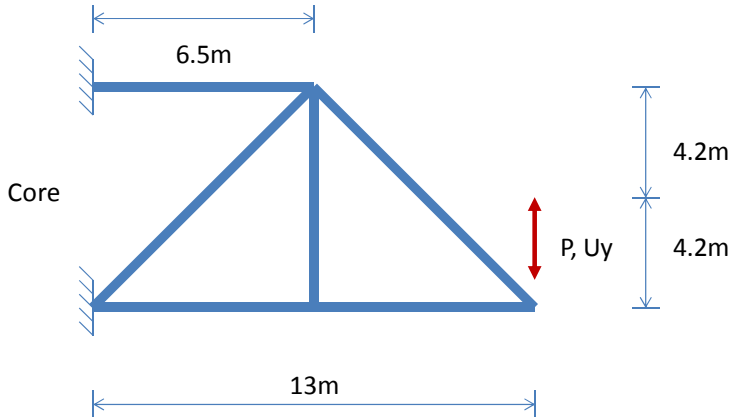

Figure 5a. Topology C

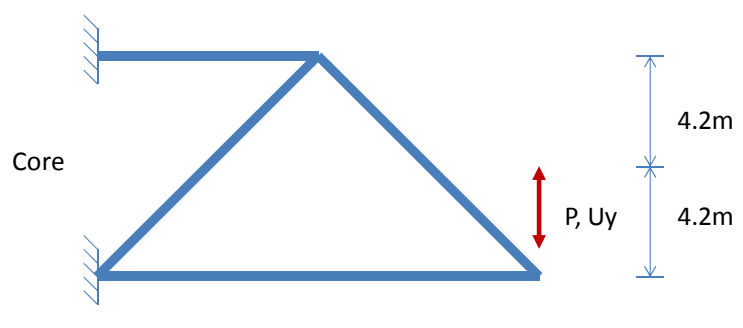

$13 m$

Figure 5b. Topology D

\section{GEOMETRIC NONLINEAR ANALYSIS AND ADVANCED ANALYSIS}

For all cases, unit downward (-ve) and upward (+ve) load were applied to the tip of outriggers. Geometric nonlinear analysis was carried out for all options to gain a better understanding on the impact of topology to the behaviour of outriggers. Considering the robustness in obtaining solution for the critical load of outriggers and the convenient in obtaining the stiffness of outrigger, Displacement Control method is used. For all geometric nonlinear analysis, the vertical displacement at the tip of outrigger $\left(\mathrm{U}_{\mathrm{y}}\right)$ is selected as the numerical constraints parameter and all with constants displacement load steps up to $5 \mathrm{~m}$. The displacement up to $5 \mathrm{~m}$ is larger than necessary but does provide results to confirm whether or not hardening effect is present. The initial stiffness of outrigger, ${ }_{0} \mathrm{~K}_{\mathrm{T}}$ is denoted as 


$$
{ }_{0} \mathrm{~K}_{\mathrm{T}}={ }_{0} \mathrm{~F} /{ }_{0} \mathrm{U}_{\mathrm{y}}
$$

where ${ }_{0} \mathrm{~F}$ represents the load reaction at the first displacement control load step ${ }_{0} \mathrm{U}_{\mathrm{y}}$. Because displacement control method is used, ${ }_{0} \mathrm{U}_{\mathrm{y}}$ can be the same for all options and studies. Hence, the ${ }_{0} \mathrm{~F}$ obtained from the analysis is the stiffness of the outriggers. For each topology, with the consideration of geometric nonlinear effects, there are two values for the stiffness, one for download and one for upward load. For comparison purposes, all loads and displacements are taken as positive so the curves can be compared directly. For the cases where the critical point is not clear enough to be determined, reference will be made to the first and second derivatives of the load-deflection curve.

Generally speaking, the magnitude of critical load of a structure is considered to reflect the ultimate load capacity. From typical member capacity check, engineers will first determine the critical loads; calculate the effective length and then the member capacity. Therefore, before engineers calculate the member sizes, they will consider the $2^{\text {nd }}$ Order load-deflection curve as an indicator to the load capacity and the initial slope for the stiffness. Hence most engineers will consider that the higher the critical load, the higher the member capacity. To validate this concept, advanced analysis technique is also applied to determine the capacity for members. Member section capacity ratio will also be listed so that we could have a whole picture on the behaviour of each outrigger topology. In advanced analysis, NIDA version 9.0.1.0 (Build 10) [7] is used with S275 steel, initial imperfection of all members to be L/1000 and the design to Hong Kong Code [8].

\section{Topology A}

Because Topology A is symmetrical to both upward and download load at tip, option A will therefore generate only one single response curve for both load cases. The $2^{\text {nd }}$ order analysis indicates that there is minor hardening (member under tension) effect for the SHS section. For UB section, there is a minor drop in load resistance after critical load before hardening starts. A summary of analysis results for topology A for both SHS and UB sections is listed in Table 1.

Table 1. Results for Topology A

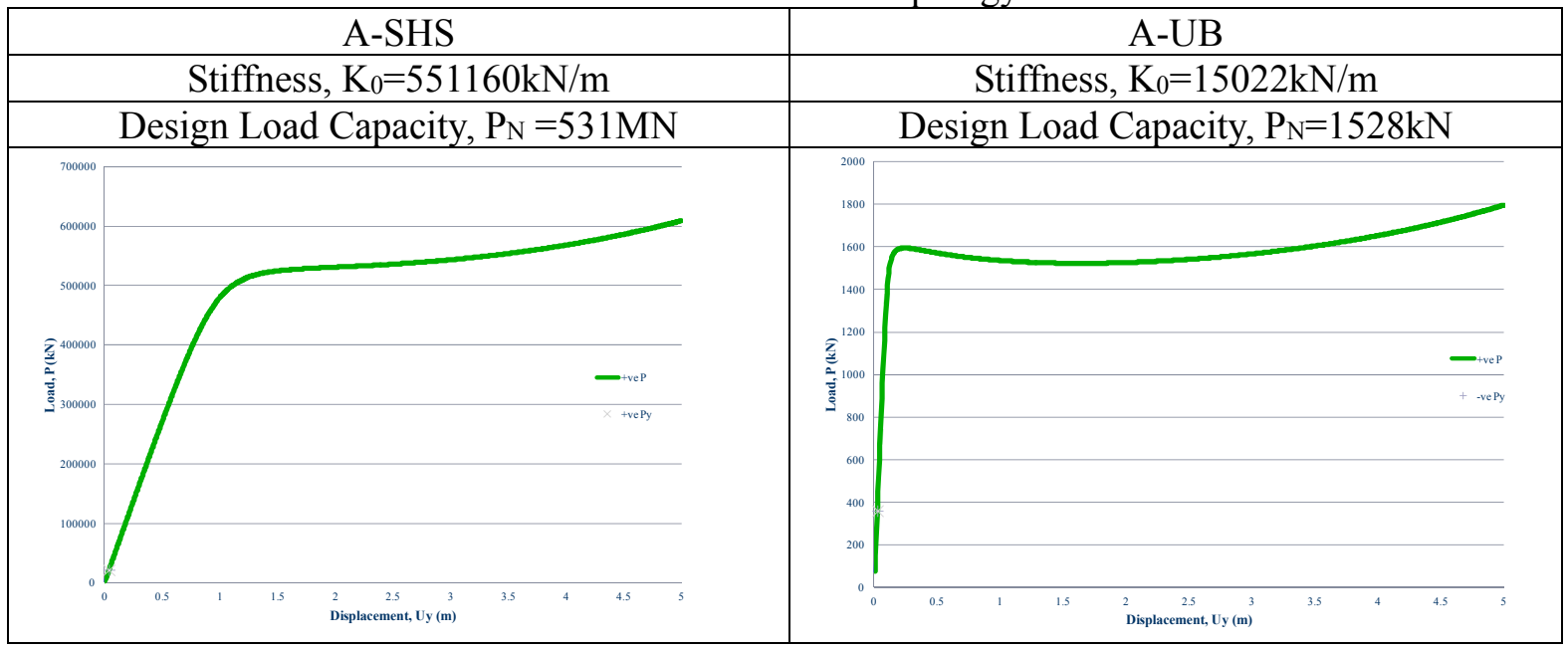




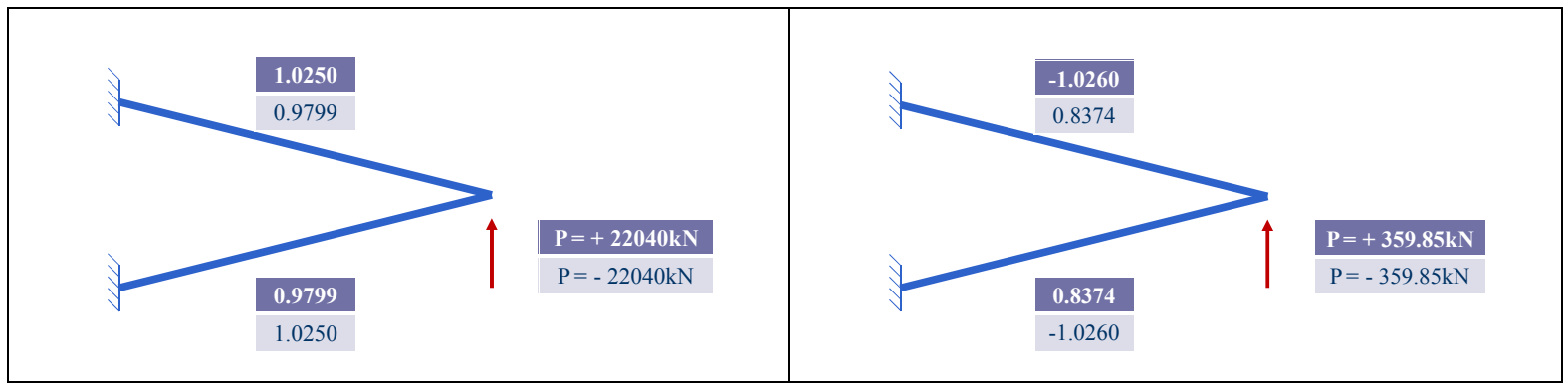

The design load capacity, $\mathrm{P}_{\mathrm{N}}$ for SHS and UB cases are $531 \mathrm{MN}$ and $1528 \mathrm{kN}$ respectively. The numbers next to members indicate the corresponding section capacity ratio for that member under "+ve" or "-ve" load P. The results show that for topology A, the section capacities for both sections are $2 \%$ difference in SHS case and 16\% in UB case. The differences in section capacities reflect the efficiency of the topology. Topology A with SHS section is relatively optimal as the section capacities for both members are close to each other in both cases. For Topology A with UB sections, the $16 \%$ difference in section capacities indicated that the geometric effect which affecting the stiffness in UB case is more significant than SHS cases. If the geometric effect is not taken into account, in elastic case, the stiffness for topology A will have only one value for both upward and downward cases. Therefore, the section capacity ratios for both SHS and UB cases will be identical.

\section{Topology B}

Although Topology B has two members and same as Topology A, it consists of one inclined member only while the other is horizontal. This topology is also common in practice as the horizontal member could also be used as floor beam. The critical load is $351 \mathrm{MN}$ for upward load and $628 \mathrm{MN}$ for downward load. The results are listed in the table 2.

Table 2. Results for Topology B

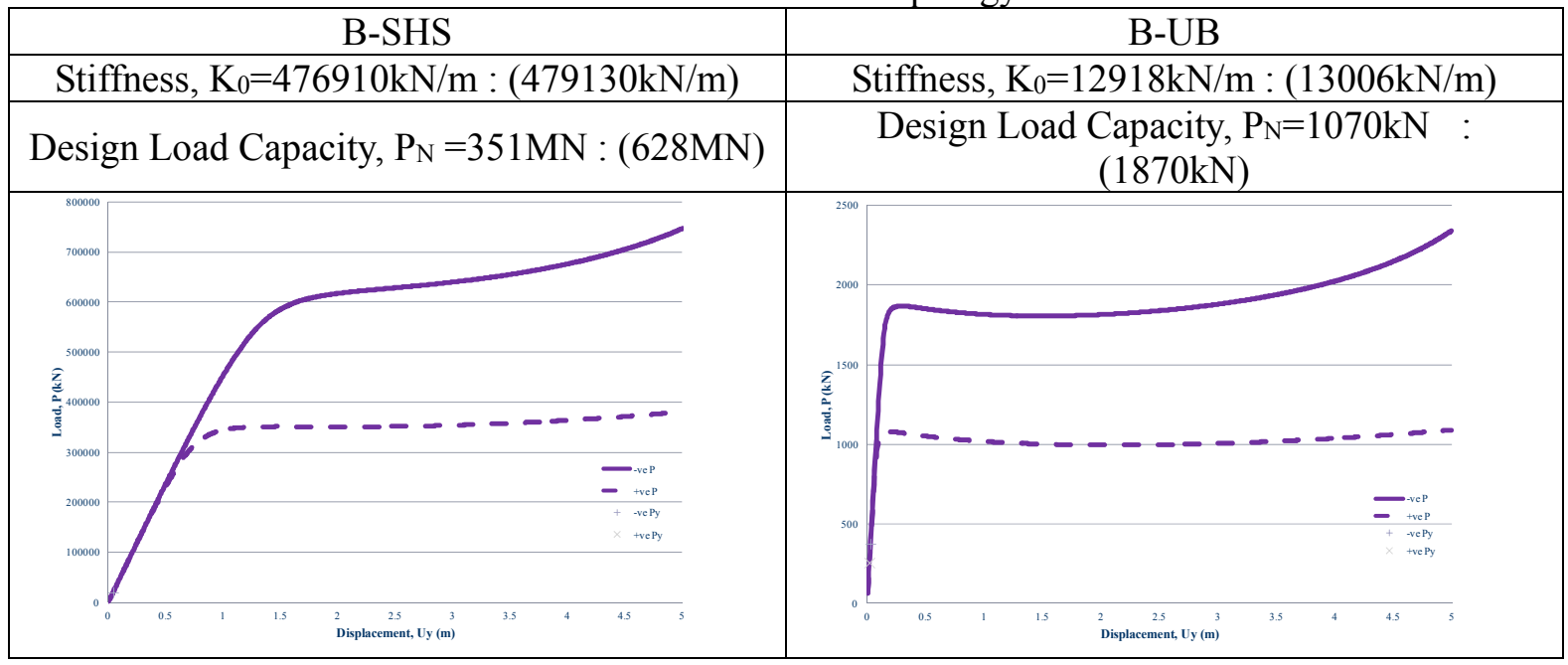




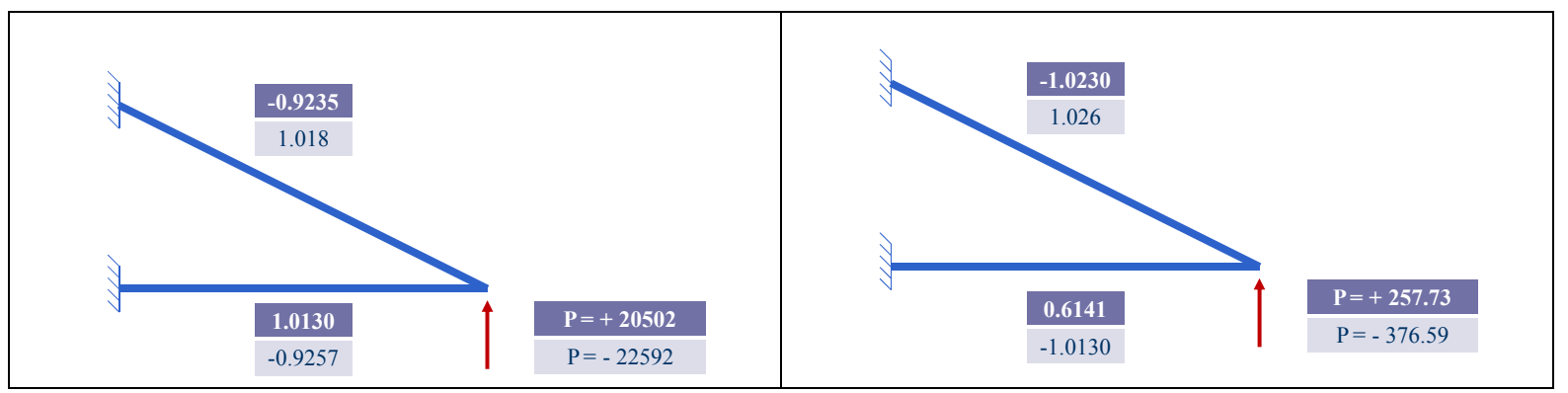

For the case of upward load, the inclined member is subject to compression while the horizontal member is under tension and vice versa. However, it is quite clear that the in the contribution of the horizontal member in case of download load could contribute more than the case of upward load. Therefore, in the case of UB sections, the section capacity ratio for the horizontal members under upward load is much lower than the downward load case. The difference in SHS section is relatively small because the stiffness in SHS model is comparatively high and again, the geometric effect is less significant.

\section{Topology C}

Through the finding of Topology A and B, engineers may conclude that outriggers should be as stiff as possible to minimize the geometric effect. Besides that, by providing very stiff members, the structures should also deliver high capacity. This concept is questionable if we consider $2^{\text {nd }}$ order effect. Therefore, Topology C and D are introduced in this study. For Topology C, there isn't a sharp critical point for the upward load case in the $2^{\text {nd }}$ order analysis. Therefore, the critical loads for both cases are based on the first and second derivatives of the load-deflection curves. The load-deflection curve also indicates hardening effect for the downward load cases is significant.

Table 3 : Results for Topology C

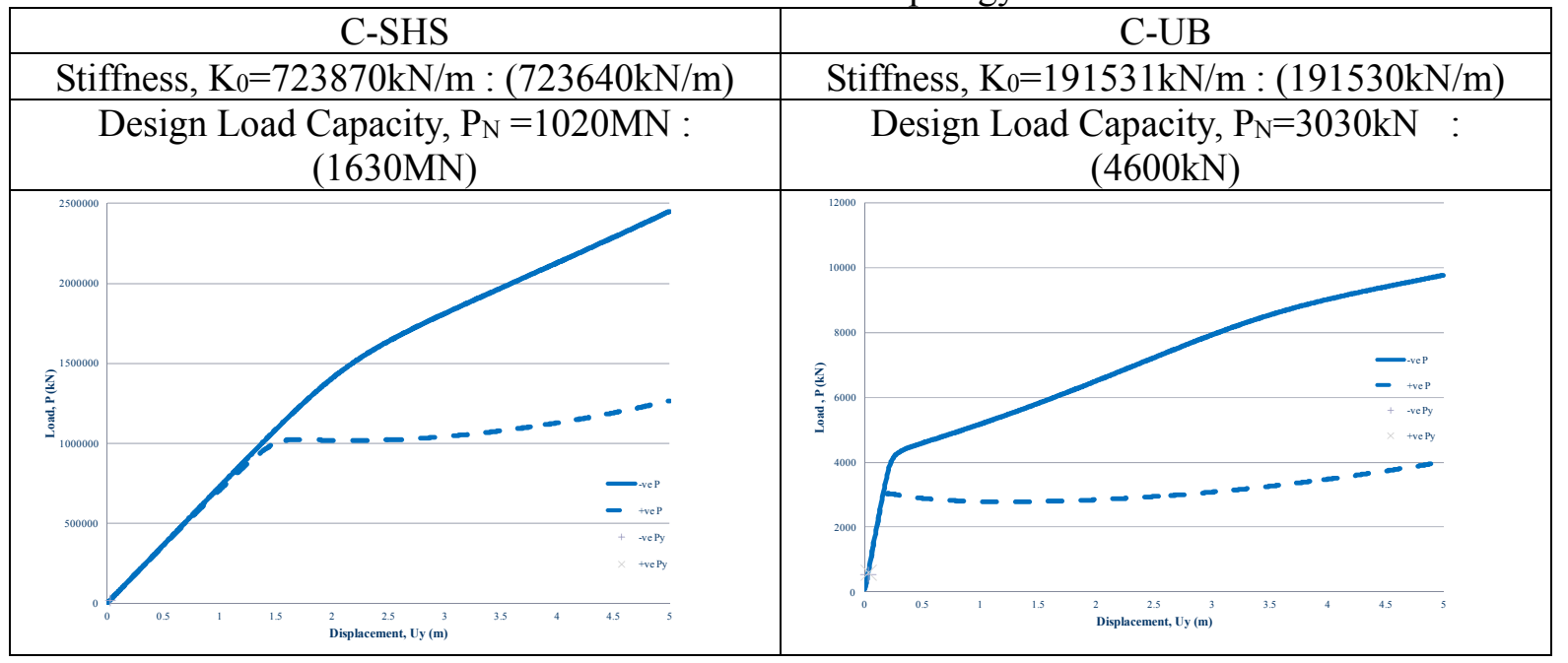




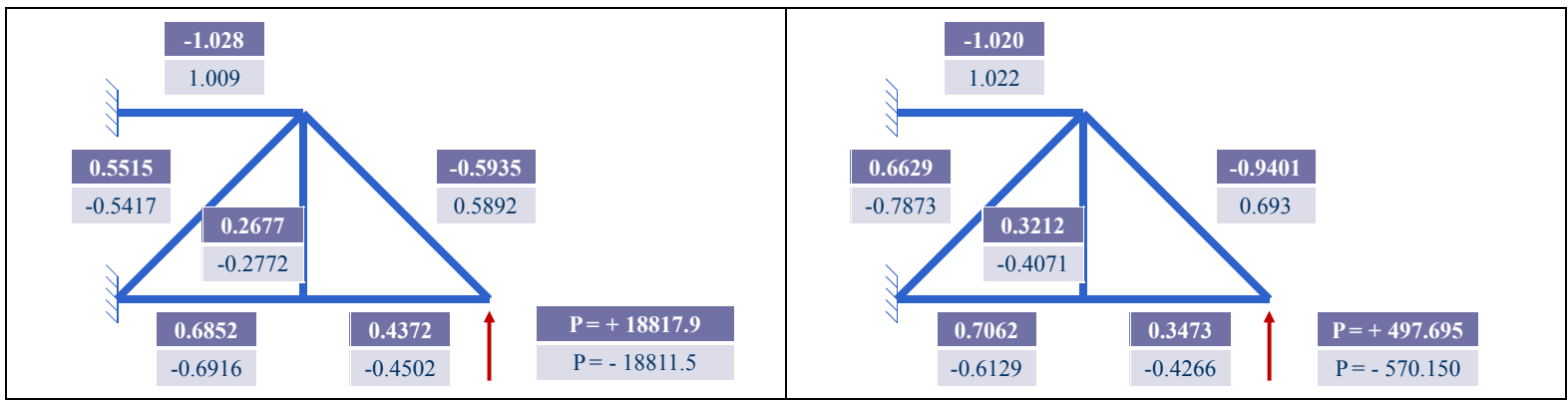

The stiffness for topology $\mathrm{C}$ models is in the order of $30 \%+$ and $27 \%+$ higher than Topology A for the case of SHS and UB models respectively. The critical loads for Topology C are also 3 times higher than Topology A. If we are going to check the final capacity, engineers will consider that Topology will provide much higher section capacity than Topology A. However, the ultimate load obtained by Topology $\mathrm{C}$ is lower than Topology A and B. By checking the capacity ratios, the most critical member is the top chord which controls the design in both upward and downward load cases. The vertical member is as low as $0.27(+\mathrm{P})$ and $0.28(-\mathrm{P})$. This indicates that the structures are not efficient and there are many dummy members. Although it delivers higher stiffness, the distribution of internal forces and stress are not even which causes a much lower ultimate load capacity than Topology A and B.

\section{Topology D}

From the finding of Topology $\mathrm{C}$, Topology $\mathrm{D}$ is proposed but with the vertical member removed. The results are listed in Table 4.

Table 4. Results for Topology D

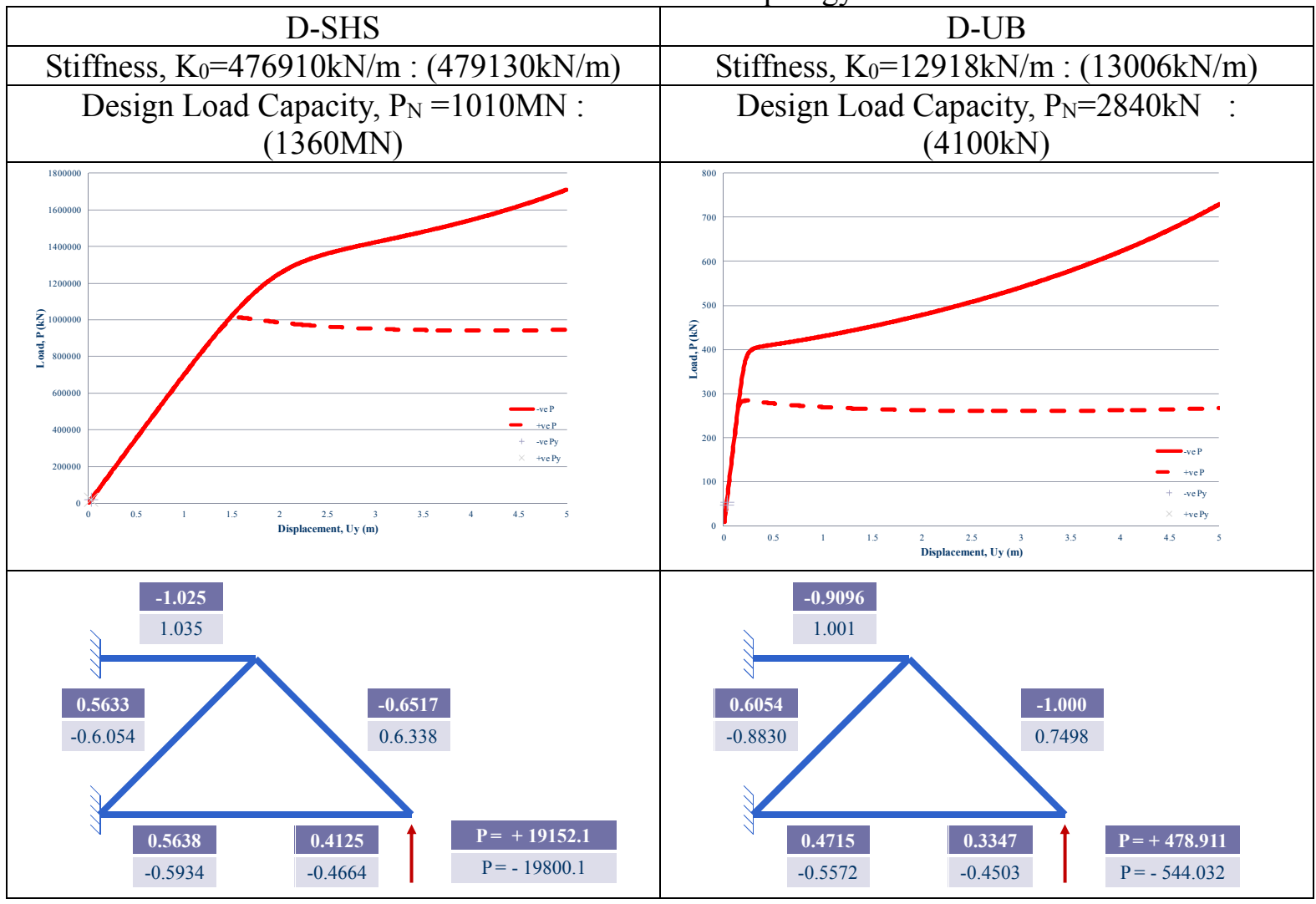


The stiffness and ultimate load capacity of Topology D is slightly less than C but of a similar order. This further proves the finding from Topology $\mathrm{C}$ as the section capacity ratios in Topology $\mathrm{D}$ at ultimate load are more evenly distribute than Topology C. It is interesting to find out that for the case of upward load, no hardening effect is found and the structure is degrading after yield for both SHS and UB cases.

\section{SUMMARY AND CONCLUSION}

For ease of comparison, the SHS and UB cases are grouped in Figure X and Y respectively. Through the figures, readers can compare the stiffness, load-deflection relationship etc. for either SHS or UB sections.

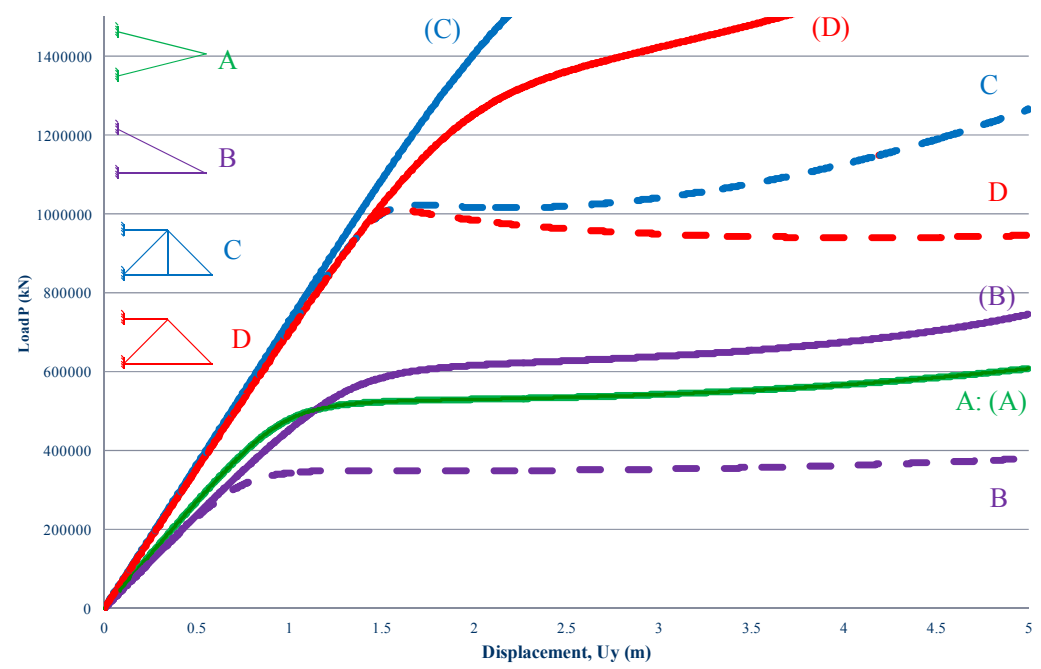

Figure 6. Load-Deflection Plot for SHS section

*For the cases of downward force, the curve will be named with a bracket ().

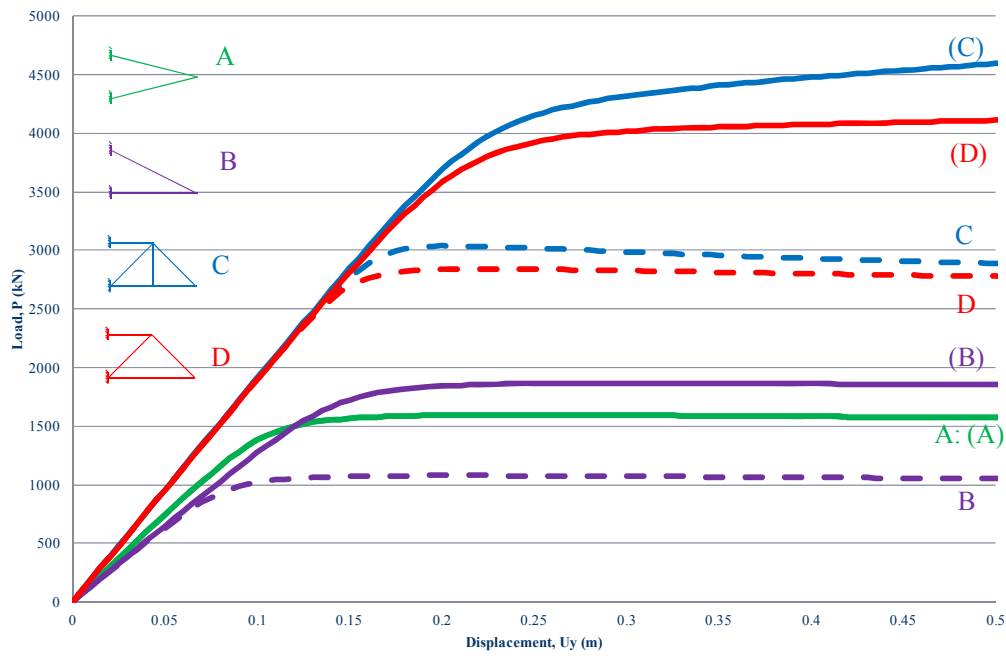

Figure 7. Load-Deflection Plot for UB section

*For the cases of downward force, the curve will be named with a bracket (). 
The results are also summarized in Table 5 and 6 . The ratio of $\mathrm{P}_{\mathrm{cr}}$ and $\mathrm{P}_{\mathrm{N}}$ in percentage were tabled where $\mathrm{P}_{\mathrm{cr}}$ is the critical load obtained from 2 nd Order analysis and $\mathrm{P}_{\mathrm{N}}$ is the ultimate load capacity obtained from advanced analysis.

Table 5. Summary of Results for Outrigger Topologies with SHS Section

\begin{tabular}{|c|c|c|c|c|}
\hline Load Direction & A-SHS & B-SHS & C-SHS & D-SHS \\
\hline \multirow{2nnyy}{*}{$+\mathrm{P}_{\mathrm{cr}}$} & \multirow{2}{*}{$531 \mathrm{MN}$} & $351 \mathrm{MN}$ & $1020 \mathrm{MN}$ & $1010 \mathrm{MN}$ \\
\cline { 1 - 3 }$-\mathrm{P}_{\mathrm{cr}}$ & & $-628 \mathrm{MN}$ & $-1630 \mathrm{MN}$ & $-1360 \mathrm{MN}$ \\
\cline { 4 - 5 }$+\mathrm{P}_{\mathrm{N}}$ & \multirow{3}{*}{$22040 \mathrm{kN}$} & $20502 \mathrm{kN}$ & $18818 \mathrm{kN}$ & $19152 \mathrm{KN}$ \\
\cline { 4 - 5 } & $(4.15 \%)$ & $(5.84 \%)$ & $(1.84 \%)$ & $(1.90 \%)$ \\
\cline { 4 - 5 } & & $-22592 \mathrm{kN}$ & $-18812 \mathrm{kN}$ & $-19800 \mathrm{kN}$ \\
& & $(3.60 \%)$ & $(1.15 \%)$ & $(1.46 \%)$ \\
\hline
\end{tabular}

Table 6. Summary of Results for Outrigger Topologies with UB Section

\begin{tabular}{|c|c|c|c|c|}
\hline Load Direction & A-UB & B-UB & C-UB & D-UB \\
\hline \multirow{2nnyy}{*}{$+\mathrm{P}_{\mathrm{cr}}$} & \multirow{2}{*}{$1582 \mathrm{kN}$} & $1070 \mathrm{kN}$ & $3030 \mathrm{kN}$ & $2840 \mathrm{kN}$ \\
\cline { 1 - 3 }$-\mathrm{P}_{\mathrm{cr}}$ & & $-1870 \mathrm{kN}$ & $-4600 \mathrm{kN}$ & $-4100 \mathrm{kN}$ \\
\cline { 1 - 3 }$+\mathrm{P}_{\mathrm{N}}$ & \multirow{3}{*}{$359.85 \mathrm{kN}$} & $257.73 \mathrm{kN}$ & $497.77 \mathrm{kN}$ & $478.91 \mathrm{kN}$ \\
\cline { 4 - 5 } & $(22.72 \%)$ & $(24.09 \%)$ & $(16.43 \%)$ & $(16.86 \%)$ \\
\cline { 1 - 3 }$-\mathrm{P}_{\mathrm{N}}$ & & $-376.59 \mathrm{kN}$ & $-550.15 \mathrm{kN}$ & $-544.03 \mathrm{kN}$ \\
& & $(20.14 \%)$ & $(11.96 \%)$ & $(13.26 \%)$ \\
\hline
\end{tabular}

A total of four practical outrigger geometries or topologies were studied. Through the finding from this study, the following conclusions are listed:

1. Unlike elastic analysis, there is more than one stiffness value for a unsymmetrical outrigger if geometric effect is taken into account as stiffness under compression is less than under tension;

2. For the same topology of outrigger, the outrigger behaviour varies according to its member stiffness. In other words, the outrigger behaviour changes if the section size changes. This means that if engineer reduces the member sizes, the design capacity is not linear proportion because the behaviour for stiff and soft members will be quite different. Similarly, enlarged sections in an outrigger structure do not always means the structure will perform better. Engineers should have a clear understanding on how the structure behaves and also the member contribution to the overall structural behaviour.

In general, the higher the structure stiffness, the less geometric effect and hence higher buckling or critical load. However, the $2^{\text {nd }}$ order critical load of a structure and stiffness is not directly proportional to the ultimate load capacity of an outrigger. Therefore, higher stiffness does not always yield high ultimate load capacity. This is very important concept especially when the structure is under cyclic load (e.g. seismic cases). The above finding and conclusion do not just apply to outrigger structures but also all slender structures. From the study of four topologies of outrigger system which considered the $2^{\text {nd }}$ order geometric effect, material nonlinearity and also design load capacity, the topology of outriggers should be as simple and symmetrical as possible. If stiffness must be increased, it is suggested to enlarge the member size instead of changing the topology. However, engineers must be aware that the internal forces within a structure change according to its stiffness. The actions may cause a member, which is previously controlled by axial force, to become moment controlled etc. A good understanding in outriggers behaviours is always needed. Among all four topologies, Topology A is possibly the best option and B be the second choice. 


\section{ACKNOWLEDGEMENT}

The author would like to express his thanks and support to Hong Kong Polytechnic University in providing an excellent research environment during the author's sabbatical leave, Prof. S.L. Chan in allowing me to use NIDA software for this study and for his valuable comments on this manuscript.

\section{REFERENCES}

[1] Mir, M. Ali and Kyoung, Sun Moon, "Structural Developments in Tall Buildings: Current Trends and Future Prospects", Architectural Science Review, 2007, Vol. 50, No. 3 pp. 205-223.

[2] Shankar Nair, B. "Belt Trusses and Basements as "Virtual" Outriggers for Tall Buildings", 4th Quarter, Engineering Journal, 1998, AISC.

[3] Taranath, B.S., "Structural Analysis \& Design of Tall Buildings", McGraw-Hill, 1988.

[4] Stafford Smith, B and Coull, A, "Tall Building Structures- Analysis and Design", John Wiley \& Sons, INC, 1991

[5] Gerasimidis S., Efthymiou E. and Baniotopoulos C.C., "Optimum Outrigger Locations of High-rise Steel Buildings for Wind Loading”, 5th European and African Conference on Wind Engineering (Proceedings), 2009

[6] Fawzia, S., Nasir, A. and Fatima, T., "Study of the Effectiveness of Outrigger System for High-Rise Composite Buildings for Cyclonic Region”, Vol. 60, World Academy of Science, Engineering and Technology, 2011.

[7] http://www.nida-naf.com

[8] Code of Practice for the Structural Use of Steel 2011, Buildings Department, Hong Kong SAR Government. 